Ann. Génét. Sél. anim., I973, 5 (I), I35-I42.

\title{
REALIZED GENETIC PARAMETERS FOLLOWING SELECTION \\ IN TRIBOLIUM CASTANEUM IN TWO ENVIRONMENTS
}

\author{
G. W. FRIARS, B. N. NAYAK and J. F. HURNIK \\ Department of Animal and Poultry Science, \\ University of Guelph, \\ Guelph, Ontario, Canada
}

\section{SUMMARY}

Heritabilities and genetic correlations were estimated in a population of Tribolium castaneum, where larva weight and offspring number were measured in one base and eight selected generations. Control lines (each represented by 50 single-pair matings) and lines selected for larva weight or offspring number (each represented by 25 single-pair matings) were replicated twice in both a wet and a dry environment.

The results indicated a decline over generations in the realized heritability of larva weight in both the wet and dry environments. The realized genetic correlations between larva weight in the wet as opposed to the dry environment indicated that genotypes affecting this trait were not specific to either environment.

The realized genetic correlations between larva weight and offspring number were positive and decreasing under selection in the wet environment. By contrast, in the dry environment, the estimates of this realized correlation were near zero and increasing slightly under selection.

The simultaneous improvement of more than one trait in animal or plant populations has prompted wide use of different versions of the selection index as formulated by HAZEL (I943). Estimates of parameters represented by either genetic correlations and heritabilities or by genetic and phenotypic variances and covariances are needed in constructing such indexes.

The model of LERNER (I958) indicated that selection would tend to decrease positive genetic correlations, even allowing for a shift from positive to negative. Trends in genetic correlations, observed by FrIARS, BoHREN and McKeAN (I962) in a selection experiment with chickens, support the hypothesized changes of LERNER. However, BOHREN, HILI and ROBERTSON (I966) developed models and conducted computer simulated selection experiments which suggested that the direction of change in genetic correlations was, in fact, gene frequency dependent. A pertinent conclusion of these latter workers was that, with existing theory, the prediction 
of correlated responses is likely to be much poorer than the prediction of direct responses, unless genetic parameters are estimated in each generation. In this connection, the degree to which inaccuracies of estimates affect genetic progress has been dealt with by MAO (I97I). Ultimately, genetic progress is reflected in realized heritabilities and genetic correlations.

The study reported here represents an investigation of the behavior of realized heritabilities and genetic correlations in a controlled selection experiment with Tribolium castaneum.

\section{MATERIALS AND METHODS}

\section{Experimental}

Details of the experiment have been presented by Friars, NAYAK, Jui and RAKTOE (I97I). In general, control lines comprised of 50 single pairs, each contributing a daughter and a son to the next generation, were maintained by random mating in one base and eight selected generaions in each of a wet ( $75 \pm 3 \mathrm{p}$. Ioo relative humidity) and a dry environment ( $50 \pm 5 \mathrm{p}$. IOO $\mathrm{RH}$ ). Simultaneously, four lines (selected for larva weight in wet, selected for larva weight in dry, selected for offspring number in wet, and selected for offspring number in dry) were maintained with 25 single pair matings in each generation.

Each of the four lines were tested in both the wet and dry environments in each generation. Two replicates of the experiment were separated by a time interval of approximately six weeks.

\section{Parameter Estimation}

Realized heritabilities were estimated by using the difference in the means of control and selected lines in each generation divided by the selection differential cumulated across generations. Realized genetic correlations were estimated by using the deviations of the selected from the control lines as measures of direct and correlated responses to selection in modifications of the formula of FALCONER, I960) where :

$$
r_{\mathrm{A}}=\frac{\mathrm{CR}}{\mathrm{R}} \frac{\bar{i}_{\mathrm{C}} h_{\mathrm{C}}}{i_{\mathrm{R}} h_{\mathrm{R}}}
$$

$r_{\mathrm{A}}=$ estimated realized genetic correlation,

$\mathrm{CR}=$ correlated response,

$\mathrm{R}=$ direct response,

$\bar{i}=$ cumulated standardized selection differential,

$h=$ square root of realized heritability.

Subscripts $\mathrm{C}$ and $\mathrm{R}$ are for correlated and direct traits respectively.

$\widehat{r}_{\mathbf{A}}^{\prime}=$ realized genetic correlation estimated by reciprocating the traits in which direct and correlated responses to selection were observed.

The product of $\widehat{r}_{A}^{\prime} \cdot \widehat{r}_{A}=\left(\frac{C R_{X} C_{Y}}{R_{X} R_{Y}}\right) I / 2$ provided a joint estimate of the genetic correlation between the two traits $\mathrm{X}$ and $\mathrm{Y}$.

\section{RESULTS}

\section{Heritabilities}

The heritability estimates of larva weight derived by means of mid-parentoffspring regression in the control populations (table I) fluctuate considerably bet ween generations. However, the realized estimates of heritability (fig. I) are slightly 
Estimates of heritability of lavva weight

by mid-parent-offspring regressions in control populations

Estimations de l'héritabilité du poids des larves par régression des descendants sur la moyenne des parents dans les populations témoins

\begin{tabular}{c|c|c}
\hline \hline Generation & Wet environment & Dry environment \\
& & \\
\hline 1 & 0.79 & 0.65 \\
2 & 0.96 & 0.39 \\
3 & 0.14 & 0.23 \\
4 & 0.48 & 0.71 \\
5 & 0.09 & 0.23 \\
6 & 0.80 & 0.31 \\
7 & 0.37 & 0.37 \\
8 & 0.16 & 0.87 \\
\hline Mean & 0.38 & 0.47 \\
\hline \hline
\end{tabular}

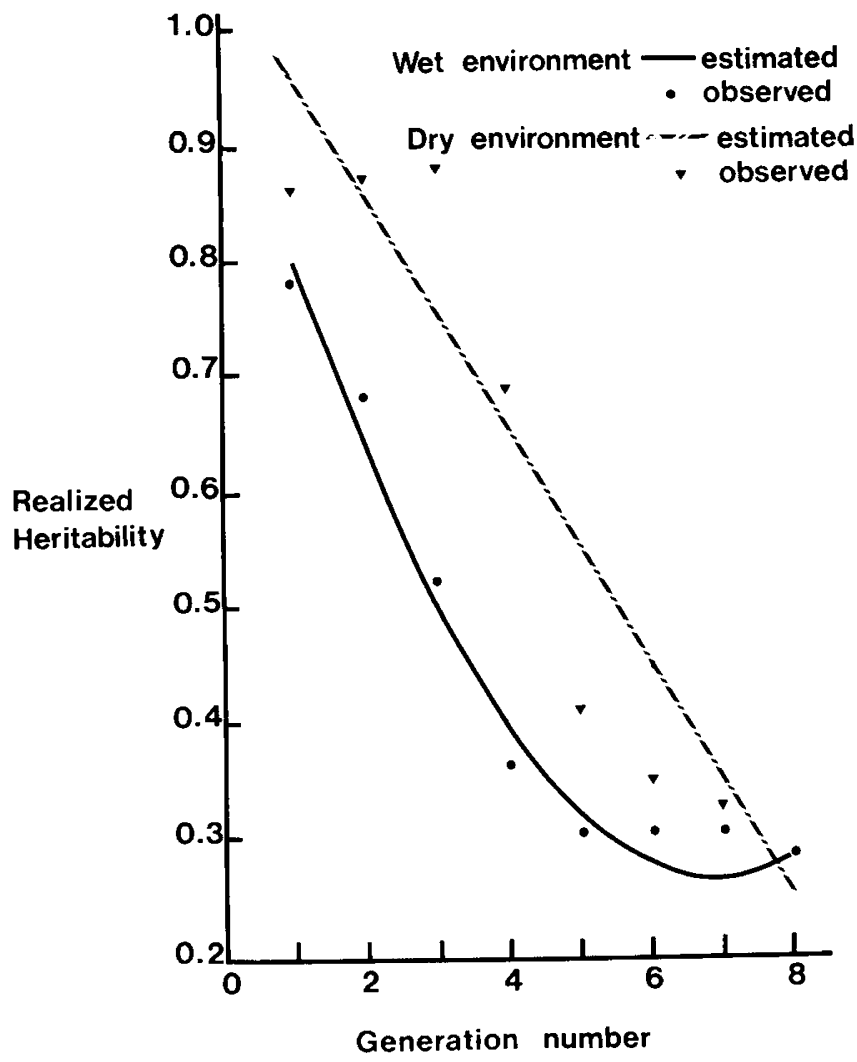

Frg. I. - Trends in realized heritability of larva weight

Tendances dans l'héritabilité réalisée du poids des larves 
higher in the dry environment and in agreement with the control population estimates although the differences between the wet and dry environments were not significant in either case when a paired $t$-test was applied. Trends in the estimates of heritability were not significant $(\mathrm{P}>.05)$ in the control populations (table $\mathrm{I})$. However, a definite decline was noted in the wet and dry environments (fig. I), where linear and not quadratic regression accounted for a significant proportion of the sums of squares $(\mathrm{P}<.05)$ in the dry environment as opposed to both linear and quadratic, after linear effects, being significant $(P<.05)$ in the wet environment.

\section{Genetic Correlations}

No trends, either between or within the two sets of estimates of the genetic correlation between larva weight in the two environments, were significant $(\mathrm{P}<.05)$ when tested by regressions and $t$-tests.

Opposite linear regressions from the two estimates of realized genetic correlations in each of the two environments (table 3) were significantly different from each other $(\mathrm{P}<.05)$. However, the geometric means of the two type of estimates deviate from one in only two cases and a paired $t$-test of the estimates revealed a non-significant difference $(\mathrm{P}<.05)$.

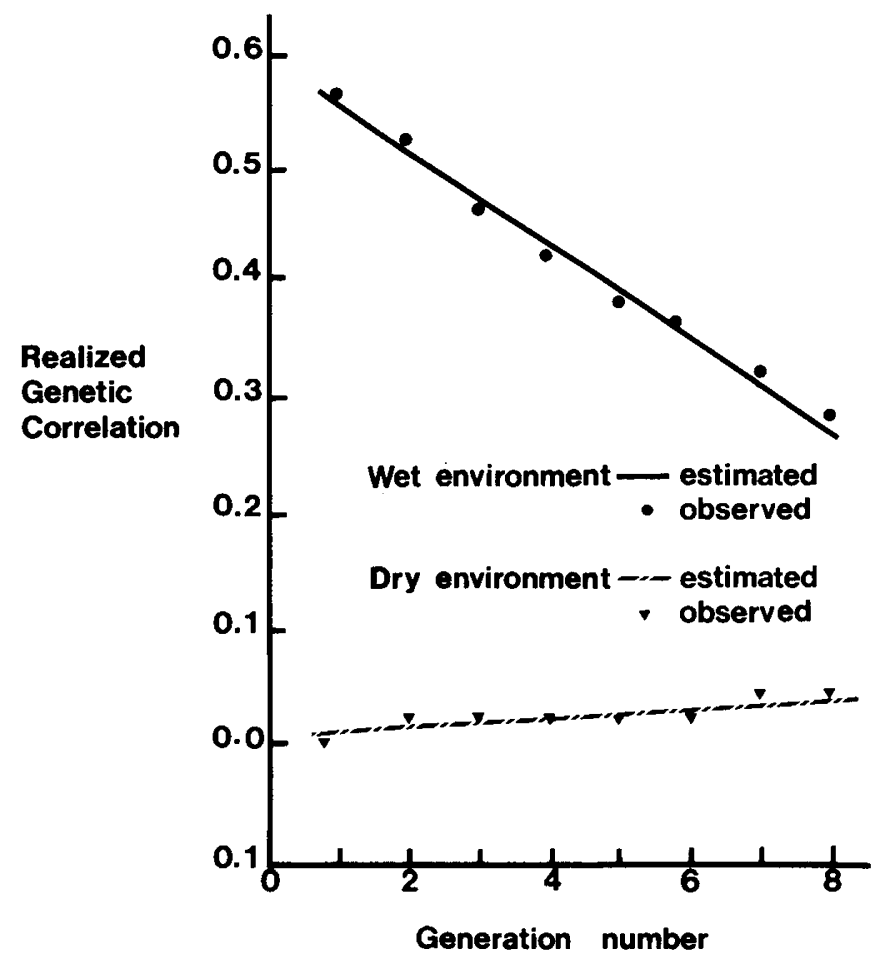

FIG. 2. - Trends in realized genetic correlation between larva reight and offspring number

Tendances dans la corrélation génétique réalisée entre le poids des larves et le nombre de descendants 
Estimates of the realized genetic correlation between larva weight and offspring number differ consistently between the wet and dry environments (fig.2). The estimates in the dry environment were close to zero and showed a slight increase while a definite decline from an initial estimate of about .6 was noted in the wet environment. The opposite slopes were both significant $(\mathrm{P}<.05)$.

\section{DISCUSSION}

\section{Heritabilities}

The standard errors of heritabilities estimated in the control populations would be expected to be higher than the realized heritability estimates according to the derivations of HILL (I97I). Such would appear to be the case through comparisons of table $I$ and figure $I$. The cumulation of selection intensities over generations has the effect of generating a lack of independence between the generation estimates of realized heritabilities. Similarly, the differences between the regressions in the selected and control lines are not independent from one generation to the next.

The values of estimated realized heritabilities used here suggest a declining rate of realized progress. These results coud be reflecting the error of the difference between the regressions of the control and selected lines (FrIARS, NAYAK, JUI and RAKTOE, I97I) where for instance errors in the estimates of genetic gain would be enlarged in the later generations as differences between the predicted values in the control and selected lines increased. However, a similar result was noted in both the wet and dry environments.

\section{Genetics Correlations}

The lower values of the genetic correlations, as estimated by the product moment correlations between full sib means in the wet and dry environments (table 2) as opposed to the realized estimates (table 3), are reasonable in light of the fact that mean family size ranged from about five to nine. In fact, ROBERTSON (I959) suggested much larger numbers per family to reduce the error of such correlation estimates to acceptable magnitudes. The small year to year variation in realized genetic correlations, similar to realized heritabilities, reflects the cumulative effects between years (fig. 2).

The reverse trends in the two types of correlation estimates (table 3) could, similarly to the suggested bias in the realized heritability estimates, be attributed to differences in regressions of control and selected lines in either the direct or correlated traits. Hence, one can only conclude that the genotypes selected for high pupa weight in the wet environment produced high pupa weight equally well in the dry environment, or vice versa.

Contrary to any consistent trend in estimates of the genetic correlation between larva weight in the wet and dry environment, the realized genetic correlation between larva weight and offspring numbers in the wet environment (fig. 2) showed a decline. This trend is similar to that where the genetic correlation between juvenile body 
Estimates of genetic correlations between lavva weights measured in two environments

Estimations des corrélations génétiques

entre poids des larves mesurés dans deux environnements

\begin{tabular}{c|c|c}
\hline \hline Generations & \multicolumn{2}{|c}{$\begin{array}{c}\text { Correlation of Family Means } \\
\text { in the Two Environments }\end{array}$} \\
\cline { 2 - 3 } & $\begin{array}{c}\text { Larva weight selected } \\
\text { in the wet and tested } \\
\text { in the dry }\end{array}$ & $\begin{array}{c}\text { Larva weight selected } \\
\text { in the dry and tested } \\
\text { in the wet }\end{array}$ \\
\hline 1 & 0.43 & 0.34 \\
2 & 0.57 & 0.88 \\
3 & 0.64 & 0.64 \\
4 & 0.66 & 0.26 \\
5 & 0.57 & 0.53 \\
6 & 0.43 & 0.23 \\
7 & 0.69 & 0.69 \\
\hline 8 & 0.51 & 0.47 \\
\hline Mean & 0.56 & \\
\hline
\end{tabular}

TABLE 3

Estimates of realized genetic correlation $\left(\widehat{r}_{\mathrm{A}}\right)$

between the performance of lavva weight in the wet and dry environment (Friars, Nayak, Jui and Raktoe, i97I)

Estimations de la corrélation génétique réalisée $\left(\widehat{\gamma}_{\mathrm{A}}\right)$

entre le poids des larves dans l'environnement humide et dans l'environnement sec

\begin{tabular}{|c|c|c|c|}
\hline Generation & $\hat{r}_{\mathrm{A}}$ & $\hat{r}_{\mathbf{A}}^{1}$ & Geometric mean \\
\hline 1 & 1.68 & 0.60 & 1.00 \\
\hline 2 & 1.70 & 0.59 & 1.00 \\
\hline 3 & 1.39 & 0.72 & 1.00 \\
\hline 4 & 1.31 & 0.76 & 1.00 \\
\hline 5 & 1.02 & 0.98 & 1.00 \\
\hline 6 & 0.46 & 1.15 & 0.73 \\
\hline 7 & 0.67 & 1.21 & 0.90 \\
\hline 8 & 0.83 & 1.20 & 1.00 \\
\hline Arithmetic mean & 1.13 & 0.90 & 0.94 \\
\hline
\end{tabular}

$\hat{r}_{\mathrm{A}}$ estimated considering larva weight in the dry environment as direct and the same trait in the wet environment as the correlated trait.

$\hat{r}_{A}^{1}$ estimated considering larva weight in the wet environment as direct trait and larva weight in the dry environment as the associated trait. 
weight and egg production switched from positive to negative in the course of a nine ganeration selection experiment with chickens (FRIARS, BOHREN and McKEAN, I962). However, McNARY (I959) found no such trends in similarly estimated genetic correlations between pupa weights measured in wet and dry environments.

In contrast to the wet environment, the most striking feature of the realized genetic correlations between larva weight and offspring number in the dry environment is the close proximity to zero, with a slight tendency toward an increase (fig. 2). The dry environment yielded much lower means than the wet for both traits (FrIARs et al., I97I). The possibility that a high level of performance is needed to allow full expression of the genetic correlation between two traits is one tenable hypothesis. Such a hypothesis is supported by the findings of HICKs (I958) in chickens where the genetic correlation between egg number and body weight was negative in years favouring good performance but positive in poor years.

Reçu pour publication en décembre 1972.

\section{ACKNOWLEDGEMEN'T}

The financial support of the Ontario Ministry of Agriculture and Food and the National Research Council of Canada is gratefully acknowledged. The comments of Dr. Ian McMillan have been very heepful in the preparation of this paper.

\section{RÉSUMÉ}

INFLUENCE DE LA SÉLECTION DANS DEUX ENVIRONNEMENTS SUR L,ES PARAMÈTRES GÉNÉTIQUES CHEZ TRIBOLIUM CASTANEUM

Les héritabilités et les corrélations génétiques ont été estimées dans une population de $T r i$ bolium Castaneum, où le poids des larves et le nombre de descendants étaient mesurés dans une population de base et huit générations soumises à sélection. Des lignées " contrôle " (représentées chacune par 5o couples de parents) et des lignées sélectionnées pour le poids des larves ou le nombre de descendants (représentées chacune par 25 couples de parents) étaient répétées deux fois, d'une part dans un environnement humide, d'autre part, dans un environnement sec.

Les résultats indiquent un déclin, au cours des générations, de l'héritabilité du poids des larves à la fois dans l'environnement humide et dans l'environnement sec. Les corrélations génétiques entre les poids larvaires dans les milieux humides et secs indiquent que les génotypes affectant ce caractère n'étaient pas spécifiques pour l'un ou l'autre des deux milieux.

Les corrélations génétiques entre le poids des larves et le nombre des descendants étaient positives et allaient en diminuant sous l'effet de la sélection dans l'environnement humide. Par contraste, dans l'environnement $\mathrm{sec}$, les estimations de cette corrélation étaient proches de zéro et augmentaient légèrement du fait de la sélection.

\section{REFERENCES}

Bohren B. B., Hill W. G., Robertson A., 1966. Some observations on asymetrical correlated responses to selection. Gen. Res., 7, 44-52.

FAlconer D. S., I96r. Introduction to quantitative Genetics. Oliver and Boyd, Edinburg, London.

Friars G. W., Bohren B. B., McKean H. E., 1962. Time trends in estimates of genetic parameters in a population of chickens subjected to multiple objective selection. Poul. Sci., 41, I773-I784. 
Friars G. W., Nayak B. N., JUi P. Y., Raktoe B. L., 197I. An investigation of genotype environment interaction in relation to a selection experiment in Tribolium castaneum. Can. Jour. Gen. Cytol., 13, x44-ז54.

Hazel L. N., I943. The genetic basis for constructing selection indexes. Genetics, 28, 476-490.

Hicks Amp. F. Jr., I958. The interrelationships of mature body weight with egg number, egg weight and egg shape in chickens. Poul. Sci., 37, I2II.

Hill W. G., 197r. Design and efficiency of selection experiments for estimating genetic parameters Biom., 27, 293-3II.

LERNER I. M., I958. The genetic basis of selection. xvii + 545 pp. New York. John Wiley and Sons Inc. MAO I. L., I97I. The effect of parameter estimation errors on the efficiency of index selection and on the accuracy of genetic gain prediction. $\mathrm{Ph}, \mathrm{D}$. Thesis. Cornell Univ.

MCNARY H. W., I959. The effect of environment on response to selection for body weight in Tribolium castaneum. Ph. D. Thesis, Purdue University.

Robertson A., I959. The sampling variance of the genetic correlation coefficient. Biom., 15, $469-485$. 